\title{
Morbidity after conventional dissection of axillary lymph nodes in breast cancer patients
}

Emerson Wander Silva Soares ${ }^{1,2^{*}}$, Hildebrando Massahiro Nagai ${ }^{3}$, Luis César Bredt ${ }^{3}$, Ademar Dantas da Cunha Jr ${ }^{4}$, Reginaldo José Andrade ${ }^{4}$ and Géser Vinícius Silva Soares ${ }^{5}$

\begin{abstract}
Background: Conventional axillary lymph node dissection (ALND) has recently become less radical. The treatment morbidity effects of reduced ALND aggressiveness are unknown. This article investigates the prevalence of the main complications of ALND: lymphedema, range-of-motion restriction, and arm paresthesia and pain.

Methods: This cross-sectional study included 200 women with invasive breast cancer who underwent breast-conserving surgery $(82.5 \%, \mathrm{n}=165)$ or mastectomy $(17.5 \%, \mathrm{n}=35)$ with ALND from 2007 to 2011 . Arm perimetry was used to assess lymphedema, defined as a difference $>2 \mathrm{~cm}$ in the upper arm circumference between the nonsurgical and surgical arms. Range-of-motion restriction was assessed by evaluating the degree of arm abduction. Paresthesia was measured in the inner and proximal arm regions. Arm pain was assessed by directly questioning the patients and defined as either present or absent.

Results: The average ( \pm SD) time between ALND and morbidity evaluation was $35 \pm 18$ months (range, 7-60 months). The average dissected lymph node number per patient was $14 \pm 4$ (range, 6-30 lymph nodes). Only $3.5 \%(n=7)$ of the patients presented with lymphedema. Single-incision approaches to breast tumor and ALND $(P=0.04)$ and the presence of a postoperative seroma $(P=0.02)$ were associated with lymphedema in univariate analysis. Paresthesia was the most frequent side effect observed (53\% of patients, $n=106)$. This complication was associated with increased age $(P<0.0001)$ and a larger dissected lymph node number $(P=0.01)$ in univariate and multivariate analysis. Additionally, $24 \%(n=48)$ of patients had noticeable limited arm abduction. Among the patients, 27.5\% $(n=55)$ experienced sporadic arm pain corresponding to the surgically treated armpit. In multivariate analysis, the pain risk was 1.9-fold higher in patients who underwent ALND corresponding to their dominant arm (95\% Cl, 1.0-3.7, $P=0.04)$.
\end{abstract}

Conclusion: Conventional ALND in breast cancer patients can result in unwanted complications. However, the current lymphedema prevalence is lower than that of the other analyzed side effects.

Keywords: Invasive breast cancer, Axillary lymph node metastases, Postsurgical complications, Lymphedema

\section{Background}

Axillary lymph node dissection (ALND), although controversial in specific situations, remains an integral part of surgical treatments in patients with invasive breast cancer and axillary lymph node metastases [1]. Specifically, this treatment is applicable in patients with tumors that are considered $\mathrm{N} 1$ or $\mathrm{N} 2$ according to the TNM staging

\footnotetext{
*Correspondence: ewss@ig.com.br

'Department of Gynecology, Western Paraná State University (Universidade Estadual do Oeste do Paraná, UNIOESTE), Cascavel, Paraná, Brazil

${ }^{2}$ Department of Surgical Oncology, Study and Treatment Cancer Center of Western Paraná, (União Oeste Paranaense de Estudos e Combate ao Câncer UOPECCAN), Cascavel, Paraná, Brazil

Full list of author information is available at the end of the article
}

system [2]. ALND was replaced in clinical practice by sentinel lymph node biopsy (SLNB) in patients that lack axillary lymph node involvement (N0) and some N1 patients [3], due to its reduced morbidity [4-7]. However, despite widespread mammography use for disease screening and early diagnosis, approximately one-third of patients in the U.S. suffer from tumors that have spread to the regional lymph nodes at diagnosis according to the Surveillance, Epidemiology and End Results (SEER) database [8]. In Brazil, according to National Department of Health statistics (2012), only $18 \%$ of these cancers are confined to the breast at diagnosis (pathologic stage), despite efforts to provide screening mammography for all women aged 
older than 40 years [9]. This late diagnosis means that, proportionally, more patients are submitted to ALND in Brazil than their American counterparts.

Currently, conventional ALND involves lymph node resection in levels I and II, as described by Berg [10]. Such dissections serve therapeutic functions and enable disease stage and prognosis assessments [11]. Unfortunately, ALND is primarily responsible for functional surgical treatment sequelae, including lymphedema, paresthesia, range-of-motion restriction, and pain in the arm ipsilateral to the lymph node dissection. Although esthetic sequelae that are caused by partial or total surgical breast resection can be reversed or minimized by reconstructive surgery methods that include prosthetics and tissue flaps, little can be done to correct the functional sequelae [12].

Since Halsted advocated the 'systematic cleaning out of the axilla' as an essential part of the operation 'for the cure of cancer of the breast' in 1907 [13], efforts to reduce the radicality and extent of tissue resection in ALND have been proposed. In 1948, Patey and Dyson [14] initially preserved the pectoralis major muscle but resected the pectoralis minor muscle along with ALND. Subsequently, Auschincloss [15] and Madden [16] proposed and closely described ALND with preservation of the pectoralis major and minor muscles in 1963 and 1965, respectively. The dissection of Berg level III has ceased in recent years [17], and the number of lymph nodes resected have decreased. A review of 21,992 women in the California Cancer Registry, who underwent ALND between 2004 and 2008, revealed an average of $11.4 \pm 7.4$ dissected lymph nodes per ALND [18]. In the 1960s, Auschincloss described an average of 38 lymph nodes per ALND [15]; this difference suggests that ALND has become increasingly conservative. Previous studies have shown that the incidence rates of complications and sequelae in the arm, including lymphedema, are directly related to the locoregional treatment radicality, which involves surgery and radiation therapy $[19,20]$. In the 1990s, studies showed that the incidence of lymphedema was decreasing due to more conservative approaches to the axilla [21].

Accordingly, this study aims to assess the current prevalence of ALND-associated complications in breast cancer patients.

\section{Methods}

\section{Patient recruitment}

A cross-sectional study was performed at the Cancer Study and Treatment Center of Western Paraná (União Oeste Paranaense de Estudos e Combate ao Câncer, UOPECCAN), a cancer patient treatment center in Cascavel city and a principal cancer treatment center in southern Brazil. The study was approved by the UOPECCAN Review Committee on Grant Proposals and Research Studies and the Research Ethics Committee of the State University of
Western Paraná. Two hundred patients who underwent surgeries from January 2007 to December 2011 were evaluated. In all cases, informed consent and data collection was performed through specific interview and physical examination for the research.

\section{Inclusion and exclusion criteria}

Women with histologically confirmed invasive breast carcinoma without distant metastases (M0) at diagnosis were included in this study. All patients underwent ALND associated with mastectomy or breast-conserving surgery and radiotherapy. Wherever possible, the ALND was performed by the same surgical incision used to approach the mammary tumor. When appropriate, the patients received chemotherapy, breast radiotherapy, immunotherapy, and hormonal blockade. No patient had the axillary nodal region included in the radiation field. The sequelae assessment was performed after chemotherapy or radiation therapy completion.

The exclusion criteria were defined as the presence of bilateral breast cancer, other malignancies except nonmelanoma skin cancer and deformities, fractures, or previous surgery in the upper limb ipsilateral to the ALND. In the sequelae assessment period (July 2012 to December 2012), 33 potential candidates missed the study monitoring and were not located, 32 patients died from the disease or other causes, and four patients refused to participate.

\section{Research tools}

1. Lymphedema (arm swelling)

The upper arm circumference (in $\mathrm{cm}$ ) at $15 \mathrm{~cm}$ proximal to the lateral epicondyle ipsilateral to the axilla surgery site was compared with the contralateral upper arm circumference, just as described by Veronesi et al. [22]. Lymphedema was defined as a difference $>2 \mathrm{~cm}$ in the upper arm circumference between the arm ipsilateral to the ALND and the non-surgical arm.

\section{Paresthesia}

The arm ipsilateral to the ALND was evaluated by touch response to a cotton ball on the inside of the arm at three points: proximal, medial, and distal; the resultant reaction was compared to that of the opposite arm. The patients were examined in a sitting position with the arms outstretched at 90 degrees. The evaluation result was defined as either present or absent (paresthesia).

3. Mobility

Rangeofmotion was evaluated by bilateral arm abduction with a protractor, and the categories were defined as follows: absent for 180 degrees of abduction, mild for 120 to 179 degrees of 
abduction, moderate for 90 to 119 degrees of abduction, and severe for abduction below 90 degrees.

4. Pain

The pain level was evaluated by directly asking the patient about the presence or absence of any arm pain. No pain score was used. The pain response was recorded as present or absent.

Additional data regarding patient characteristics, tumor stage, and treatment performed were obtained from medical records.

\section{Statistical analysis}

The means and standard deviation $( \pm)$ were used to assess numerical values. The associations between the variables studied (lymphedema, paresthesia, range-of-motion restriction, and pain) and the other patient characteristics were assessed using Fisher's exact test for the binary nominal variables and the Mann-Whitney test for continuous numeric variables. Multivariate analysis was performed using multiple logistic regression tests for the binary variables and multiple linear regression tests for the continuous variables. A Pvalue $<0.05$ was considered significant. The data were analyzed using the BioEstat ${ }^{\circ}$ software statistical package, version 5.3(available at, http://www.mamiraua.org.br/).

\section{Results}

The mean interval between ALND and analysis was 35 months (standard deviation, 18 months) with a range of 7 to 60 months. The average dissected lymph node number per patient was $14 \pm 4$ (range, 6-30 lymph nodes). None of the patients exhibited axillary recurrence during the analysis period. The patient and treatment characteristics are shown in Table 1.

Lymphedema was the least frequent complication and was found in only $3.5 \%(n=7)$ of patients. Paresthesia was the most frequent complication and was observed in 53\% $(\mathrm{n}=106)$ of patients. Arm range-of-motion restriction, which was observed in $24 \%(\mathrm{n}=48)$ of the patients, and pain, which was reported by $27.5 \%(n=55)$ of the interviewed patients, occurred with moderate frequency. Because $95 \%(n=190)$ of the evaluated patients received breast radiotherapy and $96 \%(n=192)$ received some type of chemotherapy to treat their breast cancer, both of these treatment modalities were excluded as potential variables from statistical analysis.

\section{Lymphedema}

The low case number in this study precluded the multivariate analysis of lymphedema with the other variables. Associations between the presence of lymphedema with single-incision breast surgery (breast-conserving surgery or mastectomy) and ALND $(P=0.04)$ or with the presence of postoperative seroma $(P=0.02)$ were found via univariate analysis (Table 2).

\section{Paresthesia}

Paresthesia, the most frequent side effect of ALND, occurred mainly in older patients and in ALND patients with the most dissected nodes (Table 3). This association was observed in both the univariate and multivariate analyses. The average age of patients with paresthesia was $58 \pm$ 11 years versus $49 \pm 10$ years for the group without paresthesia $(P<0.0001)$. On average, $15 \pm 4$ lymph nodes were dissected in the group with paresthesia versus $13 \pm 4$ lymph nodes in the group without paresthesia $(P=0.002)$.

\section{Range-of-motion restriction}

Although range-of-motion restriction, as assessed by the degree of abduction of the arm ipsilateral to ALND, was found in $24 \%(n=48)$ of patients, it was considered mild in $15 \%(\mathrm{n}=30)$, moderate in $8 \%(\mathrm{n}=16)$, and severe in only $1 \%(\mathrm{n}=2)$ of patients. The univariate analysis revealed an association between the range-of-motion restriction with single-incision breast surgery (breast-conserving surgery or mastectomy) and ALND $(P=0.02$, Table 4$)$. However, this association was not confirmed by the multivariate analysis.

\section{Pain}

Sporadic pain in the arm ipsilateral to the ALND, which was present in $27.5 \%(n=55)$ of the evaluated patients, did not associate with the other variables in a univariate analysis. However, the pain risk was 1.9-fold higher in patients who underwent ALND ipsilateral to the dominant arm $(95 \% \mathrm{CI}, 1.0-3.7 ; P=0.04)$, according to the multivariate analysis (Table 5).

\section{Discussion}

ALND's importance in the staging, prognostic assessment and local control of breast cancer has long been proven [23]. Local control of breast cancer also results in longer survival [24], and failing to 'clean' the axilla could mean a loss of disease control with distant metastases, such as that noted in the NSABP B-04 study [25]. If not for the morbidity, the need for ALND would not be debated in cases of SLNB positivity [3]. In contrast, the incorporation of SLNB in breast cancer treatment has benefited many women with the disease at an early stage, confined to the breast, avoiding ALND. This treatment course substantially decreased functional sequelae risks in the arm that result from surgical armpit manipulation. Because women are increasingly surviving breast cancer [26], ALND morbidity is generating a high social, psychological, and financial cost. 
Table 1 Clinical characteristics and treatments of the 200 patients in the study

Characteristic Number of patients (\%)

Age (years)

Mean age

$53 \pm 11$

$<50$

75 (37.5)

$\geq 50$

$125(62.5)$

Dominant arm

Right

188 (94)

Left

12 (6)

Surgery - evaluation interval

Mean time (months)

$35 \pm 18$

$<36$

$112(56)$

$\geq 36$

88 (44)

Radiation therapy

Yes

$190(95)$

No

$10(5)$

Chemotherapy

Yes

$192(96)$

No

Surgery

Mastectomy

35 (17.5)

Conservative surgery

$165(82.5)$

Dissected axilla

Right

94 (47)

Left

106 (53)

Surgery in the dominant arm

Yes

94 (47)

No

106 (53)

Incision for axillary dissection

The same as the breast's

$122(61)$

Separate

78 (39)

Status of lymph nodes

At least one metastatic

$103(51.5)$

Absence of metastases

$97(48.5)$

Lymph nodes with metastases (103)

Mean positive lymph nodes

$5 \pm 5$

$<5$

$63(61.1)$

$\geq 5$

$40(38.8)$

Dissected lymph nodes

Mean dissected lymph nodes

$<10$

$14 \pm 4$

$\geq 10$

35 (17.5)

$165(82.5)$

Postoperative seroma

$$
\text { Yes }
$$

No
Table 1 Clinical characteristics and treatments of the 200 patients in the study (Continued)

\begin{tabular}{ll}
\hline Postoperative hematoma & \\
Yes & $10(5)$ \\
No & $190(95)$ \\
Postoperative infection & \\
Yes & $9(4.5)$ \\
No & $191(95.5)$ \\
\hline
\end{tabular}

Unfortunately, $40.4 \%$ of patients in Brazil already present with stage III and IV disease at diagnosis [9]. In this study, $51.5 \%$ of the patients $(\mathrm{n}=103)$ had metastases in the axillary lymph nodes. The N0 patients who underwent ALND $(48.5 \%, \mathrm{n}=97)$ had contraindications to SLNB (for example, inflammatory breast cancer, T4 tumors, clinically positive axilla) or refused the procedure.

Currently, conservative surgery combined with breast radiation therapy is considered as effective as total mastectomy for the local control of breast cancer $[27,28]$. This combination treatment was administered to $82.5 \%$ $(\mathrm{n}=165)$ of the patients in this study. Previous studies

Table 2 Relationships between lymphedema and the other variables

\begin{tabular}{|c|c|c|c|}
\hline \multirow[t]{2}{*}{ Patient subgroups } & \multicolumn{2}{|c|}{ Lymphedema } & \multirow[t]{2}{*}{$P$ value $^{\mathrm{a}}$} \\
\hline & Yes (\%) & No (\%) & \\
\hline Mean age (years) & $54 \pm 12$ & $53 \pm 11$ & 0.82 \\
\hline Surgery - evaluation interval (months) & $34 \pm 24$ & $35 \pm 17$ & 0.84 \\
\hline Surgery & & & 0.1 \\
\hline Mastectomy & 3 & $32(16.5)$ & \\
\hline Conservative surgery & 4 & $161(83.5)$ & \\
\hline ALND incision & & & 0.04 \\
\hline The same as the breast's & 7 & $115(59.5)$ & \\
\hline Separate & 0 & $78(40.5)$ & \\
\hline Axilla status & & & 0.11 \\
\hline Positive & 6 & $97(50.2)$ & \\
\hline Negative & 1 & $96(49.8)$ & \\
\hline Surgery in the dominant arm & & & 0.25 \\
\hline Yes & 5 & $89(46.1)$ & \\
\hline No & 2 & $104(53.9)$ & \\
\hline $\begin{array}{l}\text { Positive axilla (103): number } \\
\text { of positive lymph nodes }\end{array}$ & $9 \pm 10$ & $5 \pm 4$ & 0.2 \\
\hline Dissected lymph nodes & $16 \pm 6$ & $14 \pm 4$ & 0.36 \\
\hline Postoperative seroma & & & 0.02 \\
\hline Yes & 3 & $17(8.8)$ & \\
\hline No & 4 & $176(91.2)$ & \\
\hline
\end{tabular}

${ }^{a}$ Fisher's exact test for binary nominal variables and the Mann-Whitney test for continuous numeric variables.

ALND: axillary lymph node dissection. 
Table 3 Relationships between paresthesia and the other variables

\begin{tabular}{|c|c|c|c|}
\hline \multirow[t]{2}{*}{ Patient subgroups } & \multicolumn{2}{|c|}{ Paresthesia } & \multirow[t]{2}{*}{$P$ value $^{\mathrm{a}}$} \\
\hline & Yes & No & \\
\hline Mean age (years) & $58 \pm 11$ & $49 \pm 10$ & $<0.0001$ \\
\hline Surgery -evaluation interval (months) & $34 \pm 18$ & $36 \pm 18$ & 0.32 \\
\hline Surgery & & & 1 \\
\hline Mastectomy & $19(17.9)$ & $16(17)$ & \\
\hline Conservative surgery & $87(82.1)$ & $78(83)$ & \\
\hline ALND incision & & & 0.56 \\
\hline The same as the breast's & $67(63.2)$ & $55(58.5)$ & \\
\hline Separate & $39(36.8)$ & $39(41.5)$ & \\
\hline Surgery in the dominant arm & & & 1 \\
\hline Yes & $50(47.2)$ & $44(46.8)$ & \\
\hline No & $56(52.8)$ & $50(53.2)$ & \\
\hline Axilla status & & & 0.25 \\
\hline Positive & $59(55.7)$ & $44(46.8)$ & \\
\hline Negative & $47(44.3)$ & $50(53.2)$ & \\
\hline $\begin{array}{l}\text { Positive axilla (103): number } \\
\text { of positive lymph nodes }\end{array}$ & $3 \pm 5$ & $4 \pm 5$ & 0.17 \\
\hline Dissected lymph nodes & $15 \pm 4$ & $13 \pm 4$ & 0.002 \\
\hline Postoperative seroma & & & 0.63 \\
\hline Yes & $12(11.3)$ & $8(8.5)$ & \\
\hline No & $94(88.7)$ & $86(91.5)$ & \\
\hline
\end{tabular}

${ }^{\text {a}}$ Fisher's exact test for binary nominal variables and the Mann-Whitney test for continuous numeric variables.

ALND: axillary lymph node dissection.

have shown that the type of treatment used influences the morbidity prevalence. Schünemann and Willich [19] evaluated 5,868 patients with breast cancer treated from 1972 to 1995 and demonstrated that the addition of radiotherapy to modified radical mastectomy increased the lymphedema incidence from $19.1 \%$ to $28.9 \%$. DiSipio et al. [20], in a systematic review and meta-analysis that evaluated 72 studies, associated chemotherapy with lymphedema. These two variables (radiotherapy and chemotherapy) were not evaluated in this study, because the vast majority of the patient cohort (95\% and 96\% respectively) was subjected to these therapeutic modalities.

Lymphedema is by far the most serious and difficult to treat complication that has the greatest effect on a patient's quality of life. However, lymphedema is not the only ALND-related complication. The literature primarily reports lymphedema, paresthesia, pain, and rangeof-motion restriction as complications of ALND. The risk of complications correlates positively with the radical nature of ALND [19,29].

The lymphedema incidence and prevalence described in the literature vary widely, possibly due to different measurement methods and intervals between ALND and
Table 4 Relationships between range-of-motion restriction and the other variables

\begin{tabular}{|c|c|c|c|}
\hline \multirow[t]{2}{*}{ Patient subgroups } & \multicolumn{2}{|c|}{$\begin{array}{l}\text { Range-of-motion } \\
\text { restriction }\end{array}$} & \multirow[t]{2}{*}{$P$ value } \\
\hline & Yes & No & \\
\hline Mean age (years) & $54 \pm 12$ & $53 \pm 11$ & 0.96 \\
\hline Surgery -evaluation interval (months) & $35 \pm 20$ & $35 \pm 17$ & 0.75 \\
\hline Surgery & & & 0.12 \\
\hline Mastectomy & $12(25)$ & $23(15.1)$ & \\
\hline Conservative surgery & $36(75)$ & $129(84.9)$ & \\
\hline ALND incision & & & 0.02 \\
\hline The same as the breast's & $36(75)$ & $86(56.6)$ & \\
\hline Separate & $12(25)$ & $66(43.4)$ & \\
\hline Surgery in the dominant arm & & & 0.6 \\
\hline Yes & $24(50)$ & $70(46.1)$ & \\
\hline No & $24(50)$ & $82(53.9)$ & \\
\hline Axilla status & & & 0.74 \\
\hline Positive & $26(54.2)$ & 77 (50.6) & \\
\hline Negative & $22(45.8)$ & 75 (49.4) & \\
\hline $\begin{array}{l}\text { Positive axilla (103): number } \\
\text { of positive lymph nodes }\end{array}$ & $7 \pm 6$ & $4 \pm 4$ & 0.1 \\
\hline Dissected lymph nodes & $14 \pm 5$ & $14 \pm 4$ & 0.89 \\
\hline Postoperative seroma & & & 0.78 \\
\hline Yes & $4(8.3)$ & $16(10.5)$ & \\
\hline No & 44 (91.7) & $136(89.5)$ & \\
\hline
\end{tabular}

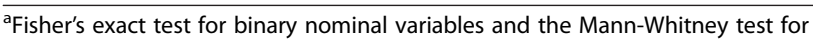
continuous numeric variables.

$A L N D$ : axillary lymph node dissection.

lymphedema measurement. DiSipio et al. [20] observed a $21.4 \%$ lymphedema incidence after analyzing 30 prospective cohort studies. Therefore, the $3.5 \%$ prevalence observed in this study is below the literature average. The lymphedema measurement method used in this study (circumference measurement) is simple, easily reproducible, and the most used approach in the medical literature. Using this method, the average lymphedema incidence observed was $14.8 \%$, as described by DiSipio et al. [20] Another study using the same lymphedema assessment criteria (upper limb measurement difference of $>2 \mathrm{~cm}$ between the arms) was conducted in Greece by Keramopoulos et al. [30] and reported a 17\% lymphedema incidence. Possible explanations for this unexpectedly low lymphedema prevalence are the lack of systematic dissection of level III, the lack of interpectoral space exploration (Rotter lymph nodes), and the attempted preservation of the pectoral muscles. Evidently, this approach results in fewer dissected lymph nodes, as noted in the present study with an average of 14 dissected lymph nodes per patient. However, none of the patients showed axillary recurrence during the analysis period. Although this number is lower than the 38 dissected lymph nodes per patient reported in the 
Table 5 Relationships between pain and the other variables

\begin{tabular}{|c|c|c|c|}
\hline Variables & Odds ratio & $95 \% \mathrm{Cl}$ & $P$-value ${ }^{\mathrm{a}}$ \\
\hline Mean age (52 years vs. 54 years) ${ }^{b}$ & & & 0.16 \\
\hline Surgery - Evaluation. interval (34 vs. 36 months) ${ }^{\text {b }}$ & & & 0.41 \\
\hline Surgery (mastectomyvs. conservative breast surgery) & 1.4 & $0.6-3.5$ & 0.38 \\
\hline Incision (single vs. separate) & 0.9 & $0.4-2.0$ & 0.95 \\
\hline Surgery (dominant arm vs. non-dominant arm.) & 1.9 & $1.0-3.7$ & 0.04 \\
\hline Axilla status (positive vs. negative) & 1.3 & $0.7-2.6$ & 0.37 \\
\hline Number of positive lymph nodes ( 6 vs. 5$)^{b}$ & & & 0.24 \\
\hline Number of dissected lymph nodes (14 vs. 14) & & & 0.65 \\
\hline Postoperative seroma (yes vs. no) & 0.7 & $0.2-2.3$ & 0.65 \\
\hline
\end{tabular}

${ }^{a}$ Multivariate analysis: multiple logistic regression tests for binary variables and multiple linear regression for continuous variables.

${ }^{\mathrm{b}}$ Multiple linear regression for continuous variables does not generate odds ratio and $\mathrm{Cl}$.

Cl: confidence interval.

1960s [15], 10 dissected lymph nodes per patient is currently considered to be an adequate minimum number $[31,32]$. It is also important to note that the time between ALND and analysis was less than 2 years in some patients. The review conducted by DiSipio et al. [20] demonstrated that lymphedema appears to increase 2 years after diagnosis of or surgery for breast cancer. The fact that no patient had the axillary nodal region included in the radiation field may also have contributed to reduce the risk of lymphedema.

Finally, another important aspect to be considered is that difference of $>2 \mathrm{~cm}$ between the arms may be too much to objectively evaluate lymphedema morbidity and an investigation with upper limb lymphoscintigraphy, for example, would have helped to detect lymphatic impairment much earlier than clinically. Therefore, this may have led to an underestimation of lymphedema prevalence in our results.

Paresthesia was the most frequent complication in this study and was found in more than half of the patients $(53 \%, \mathrm{n}=106)$. Veronesi and colleagues [22] reported a prevalence of $68 \%$, and Warmuth et al. [12] reported a prevalence of $35 \%$. This finding is related to the intercostobrachial nerve section that crosses the axilla and is transected during ALND. However, paresthesia is a minor complication that neither results in complaints nor limits the quality of life in most cases [33]. There was no intent to preserve the intercostobrachial nerve (ICBN) during ALND for the patients evaluated in the present study.

Pain and range-of-motion restriction occurred in 27.5\% $(n=55)$ and $24 \%(n=48)$ of the patients, respectively. The range-of-motion restriction was evaluated according to the degree of arm abduction, a method that has been previously used [34]. The pain and range-of-motion restriction incidence rates vary widely in literature reports. Warmuth et al. [12] identified an 8\% limitation in arm movement and a 30\% incidence of pain in 432 patients 2 to 5 years after ALND. Kootstra et al. [35] evaluated 76 women and observed that $70 \%$ had clinical relevant impairments in the shoulder and arm 7 years after ALND. It is noteworthy that $62.5 \%(\mathrm{n}=30)$ of patients who presented with range-of-motion restriction $(n=48)$ had only mild range-of-motion restriction $\left(120^{\circ}\right.$ to $179^{\circ}$ abduction). The range-of-motion restriction might be overestimated in the present study because a rangeofmotion of at least $160^{\circ}$ can be considered normal [36].

This study also found a correlation between lymphedema and single-incision surgery. This fact was not addressed in related previous studies. A possible explanation is that in breast-conserving surgery, attempts to approach the breast (quadrantectomy) and axilla (ALND) through the same incision sometimes create tunnels that complicate the correct identification of planes that involve the axilla and the preservation of the periaxillary subcutaneous tissue.

The present study also found an association between paresthesia and advanced patient age. Ververs and colleagues reported an opposite finding [37]. They discovered an inverse relationship between arm paresthesia and patient age.

The present study showed that pain, a subjective datum, was associated with surgery ipsilateral to the dominant arm. This association was also found in a previous study by Hayes and colleagues [38].

\section{Conclusion}

In conclusion, although SLNB has benefited many women with breast cancer, many patients still require ALND, despite its associated risk for morbidity. The results of this study showed that the lymphedema prevalence, the most undesirable ALND side effect, was low in relation to other evaluated symptoms. Further, larger prospective studies are required to fully assess the exact morbidity incidence following ALND. 


\section{Competing interests}

The authors declare that they have no competing interests.

\section{Authors' contributions}

EWSS conceived of the study, participated in its design and coordination, analysis and interpretation of data and helped to draft the manuscript. HMN participated in acquisition of data, have been involved in the design of the study and performed the statistical analysis. LCB participated in acquisition of data and have been involved in statistical analysis. ADCJr participated in its design and coordination and helped to draft the manuscript. RJA participated in its design and coordination and helped to revising the manuscript. GVSS participated in its design and coordination and helped to revising the manuscript. All authors read and approved the final manuscript.

\section{Acknowledgements}

The authors express their gratitude to American Journal Experts for their translation services and their gratitude to Raquel de Oliveira Bueno da Silva for her assistance. This study did not receive grant funding or other subsidies.

\section{Author details}

'Department of Gynecology, Western Paraná State University (Universidade Estadual do Oeste do Paraná, UNIOESTE), Cascavel, Paraná, Brazil. ${ }^{2}$ Department of Surgical Oncology, Study and Treatment Cancer Center of Western Paraná, (União Oeste Paranaense de Estudos e Combate ao Câncer, UOPECCAN), Cascavel, Paraná, Brazil. Department of Surgical Oncology, UOPECCAN, Cascavel, Paraná, Brazil. ${ }^{4}$ Department of Clinical Oncology, UOPECCAN, Cascavel, Paraná, Brazil. ${ }^{5}$ Department of Radiotherapy, UOPECCAN, Cascavel, Paraná, Brazil.

Received: 20 October 2013 Accepted: 15 March 2014 Published: 27 March 2014

\section{References}

1. National Comprehensive Cancer Network: NCCN Clinical Practice Guidelines in Oncology: Breast Cancer, Version 2; 2013. http://www.nccn.org/ professionals/physician_gls/pdf/breast.pdf.

2. AJCC: Breast. In AJCC Cancer Staging Manual. 7th edition. Edited by Edge SB, Byrd DR, Compton CC, Fritz AG, Greene FL, Trotti A. New York, NY: Springer; 2010:347-376.

3. Giuliano AE, Hunt KK, Ballman KV, Beitsch PD, Whitworth PW, Blumencranz PW, Leitch AM, Saha S, McCall LM, Morrow M: Axillary dissection vs no axillary dissection in women with invasive breast cancer and sentinel node metastasis: a randomized clinical trial. JAMA 2011, 305:569-575.

4. Crane-Okada R, Wascher RA, Elashoff D, Giuliano AE: Long-term morbidity of sentinel node biopsy versus complete axillary dissection for unilateral breast cancer. Ann Surg Oncol 2008, 15:1996-2005.

5. McLaughlin SA, Wright MJ, Morris KT, Sampson MR, Brockway JP, Hurley KE, Riedel ER, Van Zee KJ: Prevalence of lymphedema in women with breast cancer 5 years after sentinel lymph node biopsy or axillary dissection: patient perceptions and precautionary behaviors. J Clin Oncol 2008, 26:5220-5226.

6. Del Bianco P, Zavagno G, Burelli P, Scalco G, Barutta L, Carraro P, Pietrarota P, Meneghini G, Morbin T, Tacchetti G, Pecoraro P, Belardinelli V, De Salvo GL, GIVOM: Morbidity comparison of sentinel lymph node biopsy versus conventional axillary lymph node dissection for breast cancer patients: results of the sentinella-GIVOM Italian randomised clinical trial. Eur J Surg Oncol 2008, 34:508-513.

7. Fleissig A, Fallowfield LJ, Langridge Cl, Johnson L, Newcombe RG, Dixon JM, Kissin M, Mansel RE: Post-operative arm morbidity and quality of life. Results of the ALMANAC randomised trial comparing sentinel node biopsy with standard axillary treatment in the management of patients with early breast cancer. Breast Cancer Res Treat 2006, 95:279-293.

8. SEER Cancer Statistics Review, 1975-2009 (Vintage 2009 Populations). Bethesda, MD: National Cancer Institute; 2009. http://seer.cancer.gov/statfacts/html/breast.html.

9. Ministério Da Saúde - Instituto Nacional Do Câncer José Alencar Gomes Da Silva (INCA). Coordenação-Geral de Ações Estratégicas. Coordenação de Prevenção e Vigilância (Conprev) [Department Of Health - National Cancer Institute José Alencar Gomes Da Silva (INCA): Informativo Vigilância do Câncer n.2. Brasilia: Ministério Da Saúde; 2012. http://www1.inca.gov.br/inca/ Arquivos/comunicacao/informativo_vigilancia_cancer_n2_2012_internet.pdf.
10. Berg JW: The significance of axillary node levels in the study of breast carcinoma. Cancer 1955, 8:776-778.

11. Zarebczan DB, Neuman HB: Management of the axilla. Surg Clin North Am 2013, 93:429-444.

12. Warmuth MA, Bowen G, Prosnitz LR, Chu L, Broadwater G, Peterson B, Leight G, Winer EP: Complications of axillary lymph node dissection for carcinoma of the breast: a report based on a patient survey. Cancer 1998, 83:1362-1368.

13. Halsted WS: I. The results of radical operations for the cure of carcinoma of the breast. Ann Surg 1907, 46:1-19.

14. Patey $\mathrm{DH}$, Dyson WH: The prognosis of carcinoma of the breast in relation to the type of operation performed. Br J Cancer 1948, 2:7-13.

15. Auchincloss $\mathrm{H}$ : Significance of location and number of axillary metastases in carcinoma of the breast. Ann Surg 1963, 158:37-46.

16. Madden JL: Modified radical mastectomy. Surg Gynecol Obstet 1965, 121:1221-1230.

17. Pesce C, Morrow M: The need for lymph node dissection in nonmetastatic breast cancer. Annu Rev Med 2013, 64:119-129.

18. Olaya W, Wong J, Wong J, Morgan J, Kazanjian K, Lum S: When is a lymph node dissection a lymph node dissection? The number of lymph nodes resected in sentinel and axillary lymph node dissections. Ann Surg Oncol 2013, 20:627-632.

19. Schünemann $\mathrm{H}$, Willich $\mathrm{N}$ : Lymphödeme nach mammakarzinom [Lymphedema after breast cancer]. Dtsch Med Wochenschr 1997, 122:536-541.

20. DiSipio T, Rye $S$, Newman B, Hayes S: Incidence of unilateral arm lymphoedema after breast cancer: a systematic review and meta-analysis. Lancet Oncol 2013, 14:500-515.

21. Meek AG: Breast radiotherapy and lymphedema. Cancer 1998, 83:2788-2797.

22. Veronesi U, Paganelli G, Viale G, Luini A, Zurrida S, Galimberti V, Intra M, Veronesi P, Robertson C, Maisonneuve P, Renne G, De Cicco C, De Lucia $F$, Gennari R: A randomized comparison of sentinel-node biopsy with routine axillary dissection in breast cancer. N Engl J Med 2003, 349:546-553.

23. Moore MP, Kinne DW: Axillary lymphadenectomy: a diagnostic and therapeutic procedure. J Surg Oncol 1997, 66:2-6.

24. Punglia RS, Morrow M, Winer EP, Harris JR: Local therapy and survival in breast cancer. N Engl J Med 2007, 356:2399-2405.

25. Harris J, Ostenn R: Patients with early breast cancer benefit from effective axillary treatment. Breast Cancer Res Treat 1985, 5:17-21.

26. Siegel R, Naishadham D, Jemal A: Cancer statistics, 2013. CA Cancer J Clin 2013, 63:11-30.

27. Veronesi U, Cascinelli N, Mariani L, Greco M, Saccozzi R, Luini A, Aguilar M, Marubini E: Twenty-year follow-up of a randomized study comparing breast-conserving surgery with radical mastectomy for early breast cancer. N Engl J Med 2002, 347:1227-1232.

28. Fisher B, Anderson S, Bryant J, Margolese RG, Deutsch M, Fisher ER, Jeong $\mathrm{JH}$, Wolmark N: Twenty-year follow-up of a randomized trial comparing total mastectomy, lumpectomy, and lumpectomy plus irradiation for the treatment of invasive breast cancer. $N$ Engl J Med 2002, 347:1233-1241.

29. Burstein HJ, Winer EP: Primary care for survivors of breast cancer. N Engl J Med 2000, 343:1086-1094.

30. Keramopoulos A, Tsionou C, Minaretzis D, Michalas S, Aravantinos D: Arm morbidity following treatment of breast cancer with total axillary dissection: a multivariated approach. Oncology 1993, 50:445-449.

31. Kiricuta $\mathrm{Cl}$, Tausch J: A mathematical model of axillary lymph node involvement based on 1446 complete axillary dissections in patients with breast carcinoma. Cancer 1992, 69:2496-2501.

32. Axelsson CK, Mouridsen HT, Zedeler K: Axillary dissection of level I and II lymph nodes is important in breast cancer classification. Eur J Cancer 1992, 28:1415-1418.

33. Salmon RJ, Ansquer $Y$, Asselain B: Preservation versus section of intercostal-brachial nerve (IBN) in axillary dissection for breast cancer - a prospective randomized trial. Eur J Surg Oncol 1998, 24:158-161.

34. Ashikaga T, Krag DN, Land SR, Julian TB, Anderson SJ, Brown AM, Skelly JM, Harlow SP, Weaver DL, Mamounas EP, Costantino JP, Wolmark N, National Surgical Adjuvant Breast, Bowel Project: Morbidity results from the NSABP B-32 trial comparing sentinel lymph node dissection versus axillary dissection. J Surg Oncol 2010, 102:111-118. 
35. Kootstra JJ, Dijkstra PU, Rietman H, de Vries J, Baas P, Geertzen JH, Hoekstra HJ, Hoekstra-Weebers JE: A longitudinal study of shoulder and arm morbidity in breast cancer survivors 7 years after sentinel lymph node biopsy or axillary lymph node dissection. Breast Cancer Res Treat 2013, 139:125-134.

36. Luttgens K, Hamilton N: Kinesiology: scientific basis of human motion. 9th edition. Brown \& Benchmark: Madison, Wl; 1997.

37. Ververs JM, Roumen RM, Vingerhoets AJ, Vreugdenhil G, Coebergh JW,

Crommelin MA, Luiten EJ, van Repelaer DOJ, Schijven M, Wissing JC,

Voogd AC: Risk, severity and predictors of physical and psychological morbidity after axillary lymph node dissection for breast cancer. Eur J Cancer 2001, 37:991-999.

38. Hayes S, Battistutta D, Newman B: Objective and subjective upper body function six months following diagnosis of breast cancer. Breast Cancer Res Treat 2005, 94:1-10.

doi:10.1186/1477-7819-12-67

Cite this article as: Soares et al: Morbidity after conventional dissection of axillary lymph nodes in breast cancer patients. World Journal of Surgical Oncology 2014 12:67.

\section{Submit your next manuscript to BioMed Central and take full advantage of:}

- Convenient online submission

- Thorough peer review

- No space constraints or color figure charges

- Immediate publication on acceptance

- Inclusion in PubMed, CAS, Scopus and Google Scholar

- Research which is freely available for redistribution 